\title{
Glutamine biosynthesis and the utilization of succinate and glutamine by Rhizobium etli and Sinorhizobium meliloti
}

\author{
Sergio Encarnación, ${ }^{1}$ Jorge Calderón, ${ }^{2}+$ Alan S. Gelbard, ${ }^{3} \neq$ \\ Arthur J. L. Cooper ${ }^{4} \mathbb{S}$ and Jaime Mora ${ }^{1}$
}

Author for correspondence: Jaime Mora. Tel: +52 73 114661. Fax: +52 73175094.

e-mail: jmora@cifn.unam.mx

\footnotetext{
1 Departamento de Ecología Molecular, Centro de Investigación Sobre Fijación de Nitrógeno, Universidad Nacional Autónoma de México, Apartado Postal 565-A, Cuernavaca, Morelos, Mexico

2 Departamento de Biotecnología, Instituto de Investigaciones Biomédicas, Universidad Nacional Autónoma de México, Aparto Postal 70228, Mexico

3,4 Departments of Biochemistry ${ }^{3}$ and Neurology and Neuroscience 4 , Cornell University Medical College, New York, NY, USA
}

\begin{abstract}
Sinorhizobium meliloti 1021 and Rhizobium etli CE3 turn over nitrogen and carbon from glutamine to ammonium and $\mathrm{CO}_{2}$, respectively. Some of the ammonium released is assimilated back into glutamine, indicating that a glutamine cycle similar to that in Neurospora operates in Rhizobium. In addition, a previously unrecognized metabolic pathway in Rhizobium was discovered - namely, conversion of glutamine-carbon to $\gamma$-hydroxybutyric acid and $\beta$-hydroxybutyric acid. Additionally, some of the 2-oxoglutarate derived from glutamine catabolism in Rhizobium is converted to succinate in glutamine-containing medium. Both S. meliloti 1021 and $R$. etli CE3 oxidize succinate preferentially over glutamine when provided with both carbon sources. In contrast to Sinorhizobium meliloti 1021 and Rhizobium etli CE3, an S. meliloti double mutant that lacks both glutamine synthetase (GS) I and II preferentially oxidizes glutamine over succinate when supplied with both substrates. GSII activity is induced in wild-type S. meliloti 1021 and $R$. etli CE3 grown in succinate-glutamine medium, and this enzyme participates in the cycling of glutamine-carbon and -nitrogen. On the other hand, GSII activity is repressed in both micro-organisms when glutamine is the only carbon source. These findings show that, in medium containing both glutamine and succinate, glutamine synthesis helps drive the utilization of succinate. When glutamine is in excess as an energy-providing substrate its synthesis is restricted, allowing for more effective utilization of glutamine as an energy source.
\end{abstract}

Keywords: nitrogen metabolism, carbon metabolism, Rhizobium etli, Sinorbizobium meliloti, glutamine cycle

\section{INTRODUCTION}

Evidence for a glutamine cycle in Neurospora crassa has previously been presented (Mora, 1990). Glutamine is converted through the cycle to glutamate by glutamate

\footnotetext{
† This paper is dedicated to the memory of Dr Jorge Calderón, who died on 9 August, 1997.

$\ddagger$ Present address: Memorial Sloan Kettering Cancer Center, Williston, NY, USA.

Present address: The Winnifred Masterson Burke Medical Research Institute, White Plains, NY, USA.

Abbreviations: DT, doubling time; GDH, glutamate dehydrogenase; GS, glutamine synthetase; GOGAT, glutamate synthase; MM, minimal medium; MS, L-methionine-S, R-sulfoximine; OHB, hydroxybutyric acid; $\mathrm{PHB}$ poly- $\beta$-hydroxybutyric acid.
}

synthase (GOGAT). Glutamine is also catabolized by the glutamine transaminase- $\omega$-amidase pathway, whose products (2-oxoglutarate and ammonium) are the substrates for NADPH-dependent glutamate dehydrogenase (GDH), which synthesizes glutamate (Calderón et al., 1985). In the final step, ammonium is assimilated into glutamine amide by the action of glutamine synthetase (GS) (Fig. 1). The glutamine cycle is not futile, because it is necessary to have continuous ATP usage and drive an effective carbon flow that supports growth (Fig. 1) (Hernández \& Mora, 1986; Hernández et al., 1986).

It was of interest to determine whether the glutamine cycle operates in micro-organisms other than N. crassa, and we have focused our efforts on two species of 


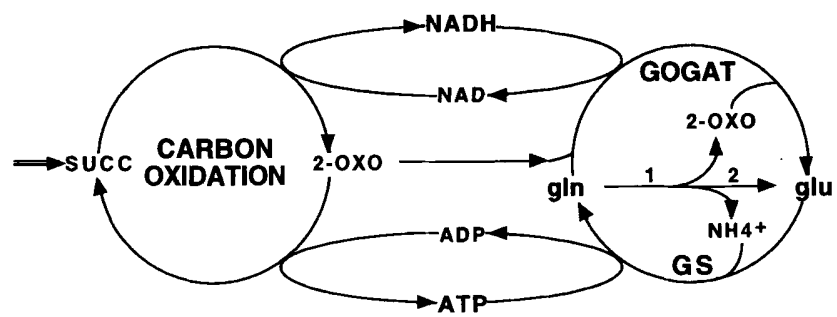

Fig. 1. Diagram of the cycling of glutamine and its relation with carbon oxidation. Abbreviations: succ, succinate; gln, glutamine; glu, glutamate; 2-oxo, 2-oxoglutaric acid; GS, glutamine synthetase; GOGAT, glutamate synthase; 1 , glutamine transaminase- $\omega$-amidase pathway; 2 , glutaminase.

rhizobia, namely Rhizobium etli and Sinorhizobium meliloti. These species associate with leguminous plants and, in contrast with most other prokaryotes, have three GSs. GSI and GSII (Darrow \& Knotts, 1977; de Bruijn et al., 1989) apparently function under different nutritional conditions, with GSI activity being induced when the organism is grown on a rich medium and GSII activity being induced and regulated by nitrogen in minimal medium (MM) (Bravo \& Mora, 1988). A third GS has been reported but the physiological conditions for its expression in the rhizobia have not been determined (Carlson et al., 1987; de Bruijn et al., 1989; Espín et al., 1990). Because $R$. etli and $S$. meliloti lack a functional NADPH-dependent GDH, ammonium is assimilated in these organisms solely by the GS-GOGAT pathway (Bravo et al., 1988). In $R$. etli, glutamine is assimilated by the enzymes of the glutamine transaminase- $\omega$ amidase pathway and contributes to the synthesis of various amino acids. Additionally, glutamine is degraded by a glutaminase to produce glutamate and ammonium (Durán \& Calderón, 1995; Durán et al., 1996; Fig. 1).

We undertook a study to determine whether cycling of glutamine-carbon and -nitrogen occurs in wild-type $R$. etli and in S. meliloti strains. Since GS is a key enzyme in the glutamine cycle, we also studied the operation of this pathway in S. meliloti mutant strains lacking GSI, GSII, or GSI and GSII activities (de Bruijn et al., 1989). Since we found that glutamine-carbon and -nitrogen are indeed recycled by these organisms (Fig. 1), we explored the metabolism of glutamine and of succinate (a good carbon source for Rhizobium), when glutamine is utilized as a carbon and/or nitrogen source. Our aim was to study the relation between carbon utilization and oxidation, and nitrogen assimilation.

\section{METHODS}

Bacterial strains. The bacterial strains used in this work were Rhizobium etli CE3 (wild-type, Bravo \& Mora, 1988) and Sinorbizobium meliloti [strains 1021 (wild-type), 1-20 ( $\ln \ln A:$ : Tn5, GSI $), 2-37,\left(g \operatorname{lnII}:: \operatorname{Tn} 5 ; \mathrm{GSII}^{-}\right)$, and $4-15$, [glnA:: (MudIIPR46)glnII::Tn5, GSI ${ }^{-}$and GSII ${ }^{-}$. The S. meliloti mutant strains have been described previously (de Bruijn et al., 1989) and were kindly provided by F. J. de Bruijn, Michigan State University, East Lansing, USA.

Growth conditions. Cultures were grown at $30^{\circ} \mathrm{C}$ in $250 \mathrm{ml}$ flasks containing $150 \mathrm{ml} \mathrm{MM}$ (Bravo \& Mora, 1988) and shaken at 200 r.p.m. The bacteria used to inoculate the cultures were grown overnight in PY rich medium (Bravo \& Mora, 1988), washed twice and inoculated into MM to give an initial $\mathrm{OD}_{540}$ of $0 \cdot 05$. The $\mathrm{MM}$ contained $10 \mathrm{mM}$ succinate as the carbon source and $10 \mathrm{mM}$ ammonium chloride or $10 \mathrm{mM}$ glutamine as the nitrogen source, as indicated in the text.

Measurement of ${ }^{13} \mathrm{~N}$-labelled metabolites. $R$. etli wild-type strain CE3 was inoculated to $\mathrm{OD}_{540} 0.2$ in succinate-ammonium MM. After $8 \mathrm{~h}$ growth, $3 \mathrm{ml}$ of the culture was centrifuged, decanted and the pellet resuspended in $100 \mu \mathrm{l}$ succinate-ammonium MM, plus $200 \mu \mathrm{L} \mathrm{L-}\left[\right.$ amide $\left.{ }^{-13} \mathrm{~N}\right]$ glutamine $[10-50 \mu \mathrm{Ci}(370-1850 \mathrm{kBq}) 50-100 \mu \mathrm{M}$, respectively]. The cell suspension was then incubated for $30 \mathrm{~min}$ and uptake of label was stopped by adding $2 \mathrm{ml}$ water. Further treatment of samples, preparation of extracts and analysis of ${ }^{13} \mathrm{~N}$ labelled metabolites by HPLC was carried out as described previously (Calderón et al., 1989). For labelling experiments with $\left[{ }^{13} \mathrm{~N}\right]$ ammonium using $R$. etli and $S$. meliloti wild-type strains, growth conditions and the concentration of label were as above, except that the cells were resuspended in $100 \mu \mathrm{MM}$ (10 mM succinate only, without an external nitrogen source), incubated for $5 \mathrm{~min}$ and treated as described above. L-[amide$\left.{ }^{13} \mathrm{~N}\right]$ Glutamine and $\left[{ }^{13} \mathrm{~N}\right]$ ammonium were prepared as described previously (Calderón et al., 1989).

Quantification of ${ }^{14} \mathrm{CO}_{2}$ evolution and determination of ${ }^{14} \mathrm{C}$ incorporated into amino acids. The ${ }^{14} \mathrm{CO}_{2}$ released from labelled succinate was determined after the addition of $0 \cdot 2 \mu \mathrm{Ci}$ $(7 \cdot 4 \mathrm{kBq})\left[1,4-{ }^{14} \mathrm{C}\right]$ succinate $\mathrm{ml}^{-1}$ (specific activity 230000 c.p.m. $\left.\mu \mathrm{mol}^{-1}\right)$ contained in $200 \mu \mathrm{l} \mathrm{ethanol} /$ water $(1: 9, \mathrm{v} / \mathrm{v})$ to a $40 \mathrm{ml}$ sample of a culture grown for $5 \mathrm{~h}$ in flasks containing $50 \mathrm{ml} \mathrm{MM}$ with succinate, plus ammonium or glutamine $(10 \mathrm{mM})$. The ${ }^{14} \mathrm{CO}_{2}$ released after the addition of label was collected for $30 \mathrm{~min}$ and quantified according to the method of Mora et al. (1972). ${ }^{14} \mathrm{CO}_{2}$ released after the addition of $200 \mu \mathrm{l}$ aqueous $0.2 \mu \mathrm{Ci}\left[\mathrm{U}^{-14} \mathrm{C}\right]$ glutamine $\mathrm{ml}^{-1}$ (specific activity 620000 c.p.m. $\mu \mathrm{mol}^{-1}$ ) to $40 \mathrm{ml}$ of a culture grown in succinate-glutamine $\mathrm{MM}$ was determined as described above. ${ }^{14} \mathrm{CO}_{2}$ evolution is expressed as c.p.m. (mg protein) ${ }^{-1}$. Protein was determined by the Lowry method. Since sparging with air was used during $\mathrm{CO}_{2}$ collection (Mora et al., 1972), the specific radioactivity of $\mathrm{CO}_{2}$ was not determined and so direct comparisons between the specific activities of label evolved as $\mathrm{CO}_{2}$ cannot be made. For the determination of amino acids, $40 \mathrm{ml}$ samples of the ${ }^{14} \mathrm{C}$-labelled cultures were prepared as described previously (Bravo \& Mora, 1988).

Labelling for determination of organic acids and amino acids. $S$. meliloti 1021 wild-type and GS mutant strains were grown in succinate-glutamine (10 $\mathrm{mM}$ each) MM. After $5 \mathrm{~h}$ growth, $40 \mathrm{ml}$ of the culture was transferred to a $125 \mathrm{ml}$ Erlenmeyer flask and a 30 min pulse of $0 \cdot 2 \mu \mathrm{Ci}\left[1,4-{ }^{14} \mathrm{C}\right]$ succinate $\mathrm{ml}^{-1}$ plus $0 \cdot 2 \mu \mathrm{Ci}\left[2,3-{ }^{14} \mathrm{C}\right]$ succinate $\mathrm{ml}^{-1}$ or $0 \cdot 2 \mu \mathrm{Ci} \mathrm{L}-\left[\mathrm{U}-{ }^{14} \mathrm{C}\right]$ glutamine $\mathrm{ml}^{-1}$ was applied to give a final specific activity twice that of labelled succinate used in the experiments in which ${ }^{14} \mathrm{CO}_{2}$ was measured. The samples were then prepared as described above for amino acid analysis. Organic acids from cell samples were separated and quantified by injecting $10 \mu \mathrm{l}$ aliquots into a Waters model 510 chromatograph (Millipore) equipped with a Waters model 490 Programmable Multiwave Length Detector. The separation and elution of organic acids was 
performed as previously reported (Encarnación et al., 1995). The fractions corresponding to the elution time of each organic acid were collected and the radioactivity incorporated was determined in a scintillation counter (Beckman LS6000SC System).

Determination of unlabelled organic acids and amino acids. Cell and medium samples (150 and $20 \mathrm{ml}$, respectively) were taken from cultures grown in succinate-glutamine $(10 \mathrm{mM}$ each) $\mathrm{MM}$ and cell pellets were prepared as described previously (Bravo \& Mora, 1988). The medium samples were concentrated as described previously (Encarnación et al., 1995). Organic acids and amino acids from cells and medium were determined by HPLC as described previously (Encarnación et al., 1995).

Determination of poly- $\beta$-hydroxybutyric acid (PHB). PHB was assayed by the spectrophotometric method of Law \& Slepecky (1961). The method yields a single, symmetrical absorption peak for crotonic acid, centred at $235 \mathrm{~nm}$, indicating that other reaction products do not interfere with the assay.

Determination of $\left[{ }^{14} \mathrm{C}\right] \mathrm{PHB}$. Batch cultures were grown as described above in succinate-glutamine MM. After $5 \mathrm{~h}$ growth, a $30 \mathrm{~min}$ pulse of $0 \cdot 2 \mu \mathrm{Ci}\left[1,4-{ }^{14} \mathrm{C}\right]$ succinate $\mathrm{ml}^{-1}$ plus $0 \cdot 2 \mu \mathrm{Ci}\left[2,3-{ }^{14} \mathrm{C}\right]$ succinate $\mathrm{ml}^{-1}$, or $0 \cdot 2 \mu \mathrm{Ci} \mathrm{L}-\left[\mathrm{U}-{ }^{14} \mathrm{C}\right]$ glutamine $\mathrm{ml}^{-1}$, was applied. Specific activity was the same as described above. After pulse-labelling, the cultures were centrifuged, washed as described in Growth Conditions, and the pellet processed for the determination of PHB (Law \& Slepecky, 1961) with the following modification: after solubilization of PHB with chloroform, two $10 \mu \mathrm{l}$ aliquots were taken; one was analysed for total PHB by the spectrophotometric method described above (Law \& Slepecky, 1961) and the radioactivity incorporated into the other was determined in a scintillation counter (Beckman LS6000SC System).

Ammonia determination. Measurement of ammonia content with an Orion (Cambridge) electrode was performed as described previously (Espín et al., 1979).

GS determination. Cell pellets from $300 \mathrm{ml}$ culture were resuspended in $1 \mathrm{ml} 10 \mathrm{mM}$ imidazole hydrochloride buffer (pH 7.4) containing $1 \mathrm{mM} \mathrm{MgCl}{ }_{2}$. After sonication (Soniprep $150)$ at $4{ }^{\circ} \mathrm{C}$ with four 45 s pulses, GS activity was measured in the crude homogenate. In some experiments, $0.5 \mathrm{mM} \mathrm{L-}$ methionine- $S, R$-sulfoximine (MS) was added to the culture medium together with labelled glutamine. MS is a potent inhibitor of GS (Ronzio \& Meister, 1968). GS was measured (synthetase activity) as described by Bender et al. (1977). The specific activity of GS is expressed as nmol $\gamma$-glutamyl hydroxamate formed $\min ^{-1}$ (mg protein) ${ }^{-1}$. GSI and II activities were distinguished by their relative heat stabilities as described previously (Darrow \& Knotts, 1977).

Reproducibility of results. The experiments reported were carried out at least twice; representative results are shown.

\section{RESULTS}

Glutamine metabolism in R. etli and S. meliloti wildtype strains in the presence of $\mathrm{L}-\left[\right.$ amide- $\left.{ }^{13} \mathrm{~N}\right]$ glutamine or $\left[{ }^{13} \mathrm{~N}\right]$ ammonium

To determine whether a glutamine cycle operates in Rhizobium, the incorporation of label derived from L[amide- ${ }^{13}$ N]glutamine into several amino acids and ammonium was determined for $R$. etli CE3 grown in succinate-ammonium MM. The relative amount of label (decay corrected) in glutamine decreased over $30 \mathrm{~min}$ following addition of the labelled pulse (Table 1). By $30 \mathrm{~min}$, the label from glutamine was incorporated into glutamine, glutamate, alanine and ammonium (Table 1). Presumably, the large amount of label in ammonium was due to 'trapping' of $\left[{ }^{13} \mathrm{~N}\right] \mathrm{ammonium}$ arising from the catabolism of $\mathrm{L}$-[amide $\left.{ }^{13} \mathrm{~N}\right]$ glutamine in a large pool of unlabelled ammonium. Of interest is the finding that label in the $\alpha$-amino group of glutamine at $30 \mathrm{~min}$ was $18.0 \%$ of the total label in glutamine (Table 1 ), despite considerable dilution of the specific activity of the metabolically generated $\left[{ }^{13} \mathrm{~N}\right] \mathrm{ammonia}$ by the large pool of unlabelled ammonium. $\mathrm{L}-\left[\right.$ amide $\left.{ }^{13} \mathrm{~N}\right]$ Glutamine is catabolized by a glutaminase and/or by the combined action of glutamine transaminase plus $\omega$-amidase (Fig. 1). In both cases, labelled nitrogen is liberated as $\left[{ }^{13} \mathrm{~N}\right]$ ammonium (Durán \& Calderón, 1995; Durán et al., 1995). Alternatively, GOGAT (Lomnitz et al., 1987; Bravo et al., 1988) catalyses the reductive transfer of the ${ }^{13} \mathrm{~N}$ label from L-[amide- $\left.{ }^{13} \mathrm{~N}\right]$ glutamine to 2-oxoglutarate to yield one molecule of unlabelled L-glutamate and one molecule of $\mathrm{L}-\left[{ }^{13} \mathrm{~N}\right]$ glutamate. Reductive amination of 2-oxoglutarate with $\left[{ }^{13} \mathrm{~N}\right]$ ammonium is unlikely to occur because $R$. etli CE3 does not contain a functional NADPH-dependent GDH (Bravo et al., 1988). L-[amine$\left.{ }^{13} \mathrm{~N}\right]$ Glutamine is then generated from $\mathrm{L}-\left[{ }^{13} \mathrm{~N}\right]$ glutamate by the action of GS. The finding of label in the amine position of glutamine indicates that the amide nitrogen of $\mathrm{L}$-glutamine is a source of both glutamine nitrogens in R. etli. For this redistribution of glutamine nitrogen to occur, synthesis and degradation of this amino acid must occur simultaneously. Finally, labelled alanine presumably arises via transamination of $\mathrm{L}-\left[{ }^{13} \mathrm{~N}\right]$ glutamine with pyruvate since this 2 -oxoacid is a preferred acceptor (Durán et al., 1995).

Further evidence for the cycling of glutamine nitrogen was obtained from experiments in which $\left[{ }^{13} \mathrm{~N}\right]$ ammonium was added to cultures of $R$. etli and $S$. meliloti wild-type strains (Table 1). After growth on succinate-ammonium MM, the cells were centrifuged and resuspended in succinate MM containing only $\left[{ }^{13} \mathrm{~N}\right]$ ammonium as the nitrogen-source (see Methods). Five minutes after suspension in this medium, a considerable amount of label was incorporated into cellular glutamate, alanine and glutamine (Table 1, columns 3, 4). Additionally, almost half the label in glutamine was present in its $\alpha$-amino group. The conversion of glutamine to glutamate can be explained by the presence of GOGAT in both $R$. etli (Bravo et al., 1988) and $S$. meliloti (Osburne \& Signer, 1980). Low-level expression of NADPH-dependent GDH occurs in $S$. meliloti, although the enzyme is non-functional since the organism does not grow in medium containing ammonium plus $5 \mathrm{mM}$ methionine sulfone [an inhibitor of GOGAT activity (Bravo et al., 1988)]. Thus, as with $R$. etli, reductive ${ }^{13} \mathrm{~N}$-amination of 2 -oxoglutarate is probably not a factor in the production of $\left[{ }^{13} \mathrm{~N}\right]$ glutamate from $\left[{ }^{13} \mathrm{~N}\right]$ ammonium in $S$. meliloti. 
Table 1. ${ }^{13} \mathrm{~N}$ Distribution of label derived from L-[amide- $\left.{ }^{13} \mathrm{~N}\right]$ glutamine and $\left[{ }^{13} \mathrm{~N}\right]$ ammonium among various metabolites

The total label incorporated into amino acids and ammonium was taken as $100 \%$.

\begin{tabular}{|c|c|c|c|}
\hline \multirow[b]{3}{*}{ Labelling time... } & \multicolumn{3}{|c|}{ Percentage of label from } \\
\hline & \multirow{2}{*}{$\begin{array}{c}\mathrm{L}-\left[\text { amide }-{ }^{-13} \mathrm{~N}\right] \text { Glutamine } \\
\text { R. etli CE3 } \\
30 \mathrm{~min}\end{array}$} & \multicolumn{2}{|c|}{$\left[{ }^{13} \mathrm{~N}\right]$ Ammonium } \\
\hline & & $\begin{array}{l}\text { R. etli CE3 } \\
5 \mathrm{~min}\end{array}$ & $\begin{array}{c}\text { S. meliloti } 1021 \\
5 \mathrm{~min}\end{array}$ \\
\hline Glutamine* & $3 \cdot 3$ & $14 \cdot 2$ & $6 \cdot 0$ \\
\hline Glutamate & $1 \cdot 1$ & $19 \cdot 6$ & $16 \cdot 2$ \\
\hline Alanine & $11 \cdot 3$ & $21 \cdot 9$ & $7 \cdot 7$ \\
\hline Ammonium & $84 \cdot 3$ & $33 \cdot 9$ & $58 \cdot 7$ \\
\hline Glutamine (amino)t & $(18 \cdot 4)$ & $(49 \cdot 3)$ & $(44 \cdot 0)$ \\
\hline
\end{tabular}

${ }^{* 13} \mathrm{~N}$ label in amine plus amide.

†Percentage of label in glutamine present in the $\alpha$-amino group.

\section{Succinate and glutamine oxidation in $R$. etli CE3, and in S. meliloti 1021 wild-type and GS mutants}

To determine how succinate and glutamine oxidation were related to each other as carbon sources and whether the oxidation of these compounds are in some way dependent on glutamine synthesis, the utilization and conversion of their carbon to $\mathrm{CO}_{2}$ was measured in the wild-type strain and the $\mathrm{GS}^{-}$mutants of $S$. meliloti. It was found that after $5 \mathrm{~h}$ growth in succinate-glutamine MM, the $S$. meliloti wild-type strain had consumed $1348 \mu \mathrm{mol}$ succinate $(\mathrm{mg} \text { protein })^{-1}$ from the medium, whereas only $694 \mu \mathrm{mol}$ glutamine $(\mathrm{mg} \text { protein })^{-1}$ had been utilized. This finding suggests that more succinate than glutamine is consumed in the strain studied.

The role of glutamine synthesis, if any, in the utilization of carbon in S. meliloti wild-type and $\mathrm{GS}^{-}$mutants was investigated. Strains were grown on succinate-glutamine $\mathrm{MM}$ and the oxidation of $\left[1,4-{ }^{14} \mathrm{C}\right]$ succinate to ${ }^{14} \mathrm{CO}_{2}$ was measured. Data on the oxidation of labelled succinate to ${ }^{14} \mathrm{CO}_{2}$ by cultures grown for $5 \mathrm{~h}$ followed by a $30 \mathrm{~min}$ pulse of the label are presented in Fig. 2(a). In comparison to the wild-type strain, only a minor decrease was observed in the amount of succinate oxidized by the $\mathrm{GSI}^{-}$mutant, while the $\mathrm{GSII}^{-}$mutant showed a $45 \%$ decrease in succinate oxidation. Succinate oxidation was decreased by $62 \%$ in the $\mathrm{GSI}^{-} \mathrm{GSII}^{-}$ mutant (Fig. 2a). When MS was added to inhibit GSIII activity (Espín et al., 1990) in the double mutant, an additional, small decrease (to $70 \%$ inhibition relative to the control) in succinate oxidation was observed (Fig. $2 \mathrm{a}$; see also below). It is important to mention that when glutamine was substituted by ammonium, more succinate was oxidized by the wild-type strain (data not shown and see Discussion).

In contrast with $\left[{ }^{14} \mathrm{C}\right]$ succinate, when a $30 \mathrm{~min}$ pulse of $\left[\mathrm{U}-{ }^{14} \mathrm{C}\right]$ glutamine was given, some glutamine was oxidized in the wild-type strain in the presence of succinate and glutamine. However, relatively more glutamine was oxidized to $\mathrm{CO}_{2}$ in the absence of GSI, slightly more if GSII was lacking, and in the mutant lacking both enzymes, the oxidation of this amino acid was increased by $76 \%$ over that of the wild-type strain (Fig. 2b). Oxidation of glutamine increased even more when MS is added to the double mutant (Fig. 2b). In addition, measurement of ammonium excretion showed that the double mutant excreted more ammonium than did the wild-type strain grown in succinate-glutamine MM (Table 2); this may be related to the high $K_{m}$ of GSIII (Chiurazzi et al., 1992; Shatters et al., 1993). Therefore, when the synthesis of glutamine is limited, the oxidation of the amino acid increases in comparison with succinate. This effect is reflected in the twofold increase in glutamine utilization [from 694 to $1389 \mu \mathrm{mol}$ ( $\mathrm{mg}$ protein $)^{-1}$ in $5 \mathrm{~h}$ ] and by the decrease in succinate utilization [from 1348 to $237 \mu \mathrm{mol}\left(\mathrm{mg}\right.$ protein) ${ }^{-1}$ in $5 \mathrm{~h}$ ] in the $\mathrm{GSI}^{-} \mathrm{GSII}^{-}$double mutant. Similar results were obtained when $\left[\mathrm{U}-{ }^{14} \mathrm{C}\right]$ glutamine oxidation was measured in the presence of glucose instead of succinate as carbon source, except that a tenfold higher concentration of glucose $(100 \mathrm{mM})$ was required to give a growth rate equivalent to that of the $S$. meliloti wildtype strain in succinate (data not shown).

The growth rate of the $S$. meliloti $\mathrm{GSI}^{-} \mathrm{GSII}^{-}$double mutant in succinate-glutamine $\mathrm{MM}$ was $18.0 \%$ slower than that of the wild-type strain (Table 3). The present data indicate that the utilization and oxidation of succinate contributes less to the growth of the double mutant than glutamine, when both substrates are present. The oxidation (albeit at a slow rate) of succinate in this double mutant may conceivably be due to the presence of GSIII, and to a residual glutamine synthesis (Espín et al., 1990). The addition of MS to the double mutant resulted in a further decrease in succinate 

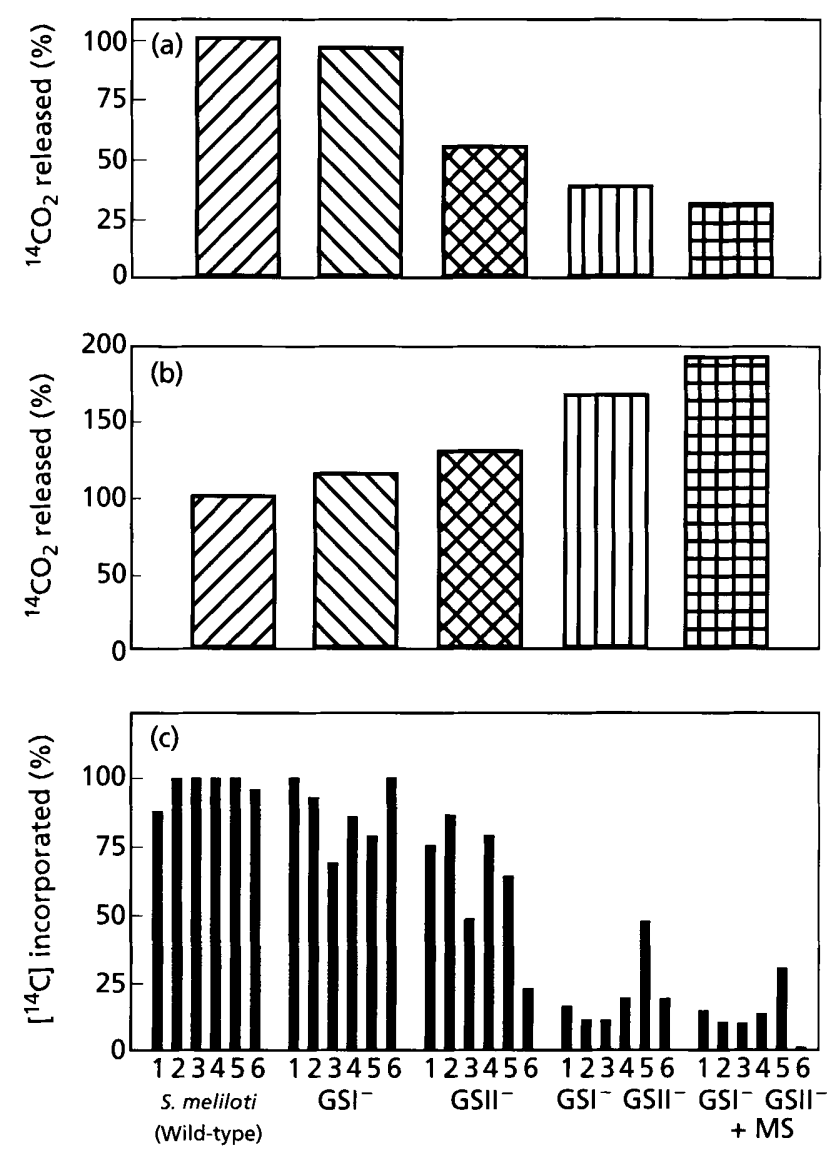

Fig. 2. Determination of ${ }^{14} \mathrm{CO}_{2}$ and ${ }^{14} \mathrm{C}$ incorporated into amino acids from wild-type and $\mathrm{GS}^{-}$mutant strains of $R$. meliloti. Cells were grown in succinate-glutamine (10 $\mathrm{mM}$ each) MM for $5 \mathrm{~h}$ and the label was added to samples of the cultures for $30 \mathrm{~min}$ as stated in Methods. (a) ${ }^{14} \mathrm{CO}_{2}$ released from $\left[1,4-{ }^{14} \mathrm{C}\right]$ succinate. (b) ${ }^{14} \mathrm{CO}_{2}$ released from $\left[\mathrm{U}-{ }^{14} \mathrm{C}\right]$ glutamine. ${ }^{14} \mathrm{CO}_{2}$ evolution in the wild-type strain was 392211 and 92211 c.p.m. (mg protein) ${ }^{-1}$, for succinate and glutamine, respectively. These values were taken as $100 \%$. (c) ${ }^{14} \mathrm{C}$ incorporated into amino acids from [1,4${ }^{14} \mathrm{C}$ ssuccinate. Wild-type specific radioactivity (c.p.m. nmol ${ }^{-1}$ ) of amino acids was: (bar 1) aspartate, 7710; (2) threonine plus serine, 3700; (3) glutamate, 680; (4) glutamine, 630; (5) glycine, 2540; (6) alanine, 1810. Wild-type specific activity incorporated into amino acids was taken as $100 \%$ with the exception of aspartate $(8742=100 \%)$ and alanine $(1886=100 \%)$, which were higher in the $\mathrm{GSI}^{-}$mutant strain. oxidation (Fig. 2a). This effect, together with the increase in glutamine oxidation in the presence of MS, results from the inhibition of GSIII (Espin et al., 1990) (Fig. 2a, b). It is expected that GSIII will provide glutamine in only very limited amounts, as indicated by the low rate of growth $[8.1 \mathrm{~h}$ doubling time (DT)] of the double mutant in succinate-ammonium MM (Table 3).

\section{Synthesis of glutamine and incorporation of label derived from $\left[1,4-{ }^{14} \mathrm{C}\right]$ succinate into amino acids}

A considerable amount of label derived from [1,4$\left.{ }^{14} \mathrm{C}\right]$ succinate was incorporated into various amino acids in the wild-type $S$. meliloti strain (which contains the full complement of GSs) (Fig. 2c). In comparison, the specific radioactivities of some amino acids were decreased in the $\mathrm{GSI}^{-}$mutant (Fig. 2c); this trend was even more noticeable in the $\mathrm{GSII}^{-}$mutant. In the latter case, the specific radioactivities were decreased for all the amino acids determined (Asp, Thr, Ser, Glu, Gln, Gly and Ala), compared to the corresponding values in the wild-type and $\mathrm{GSI}^{-}$strains (Fig. 2c). Finally, in the $\mathrm{GSI}^{-} \mathrm{GSII}^{-}$ double mutant, the relative specific radioactivities of all the amino acids (except glycine) were decreased by $80 \%$ or more compared to the values obtained for the wildtype strain. The presence of MS resulted in even lower specific radioactivities of the amino acids in the double mutant, in which, with the same type of experiment, it was shown that glutamine is degraded to ammonium, and the labelled 2-oxoglutarate supplies the carbon skeletons for the synthesis of labelled glutamate and glutamine. Thus, the catabolism of glutamine provides ammonium, which is assimilated by GS back into glutamine. 2-Oxoglutarate, derived from succinate through the TCA cycle, is converted to glutamate (via transamination reactions or the GOGAT reaction). ${ }^{14} \mathrm{C}$ labelled glutamate, in turn, is a precursor of labelled glutamine. This is in accordance with previous findings in N. crassa (Calderón et al., 1989; Calderón \& Mora, 1985). A lower overall specific activity of GS must perforce result in less incorporation of ${ }^{14} \mathrm{C}$ from labelled succinate into glutamine. Indeed, a lower specific radioactivity of glutamine was observed for the various GS mutants, as shown in Fig. 2(c). As noted above, both

\section{Table 2. Ammonium excretion from different Rhizobium strains}

Strains were grown in $M M$ with succinate-glutamine $(10 \mathrm{mM}$ each $)$ or glutamine $(10 \mathrm{mM})$ as the carbon and nitrogen source, as indicated. ND, Not determined.

\begin{tabular}{|c|c|c|c|c|c|c|c|}
\hline \multirow{3}{*}{$\begin{array}{l}\text { Growth medium } \\
\text { containing: }\end{array}$} & \multirow[b]{3}{*}{ Time $(\mathbf{h}) \ldots$} & \multicolumn{6}{|c|}{ Excreted $\mathrm{NH}_{4}^{+}\left[\mu \mathrm{mol}(\mathrm{mg} \text { protein })^{-1}\right]$} \\
\hline & & \multicolumn{2}{|c|}{$\begin{array}{c}\text { S. meliloti } \\
1021\end{array}$} & \multicolumn{2}{|c|}{$\begin{array}{l}\text { S. meliloti } \\
\text { GSI }^{-} \text {GSII }^{-}\end{array}$} & \multicolumn{2}{|c|}{$\begin{array}{l}\text { R. etli } \\
\text { CE3 }\end{array}$} \\
\hline & & 4 & 8 & 4 & 8 & 4 & 8 \\
\hline Succinate-glutamine & & $0 \cdot 2$ & $0 \cdot 1$ & $9 \cdot 0$ & $18 \cdot 0$ & $0 \cdot 1$ & $0 \cdot 2$ \\
\hline Glutamine & & $3 \cdot 9$ & $3 \cdot 7$ & ND & ND & $0 \cdot 8$ & $2 \cdot 2$ \\
\hline
\end{tabular}


Table 3. Growth (DTs) of $R$. meliloti wild-type and GS- mutant strains with different carbon and nitrogen sources

\begin{tabular}{|lccc|}
\hline Strain & \multicolumn{3}{c|}{ DT (h) in MM containing: } \\
\cline { 2 - 4 } & $\begin{array}{c}\text { Succinate- } \\
\text { ammonium }\end{array}$ & $\begin{array}{c}\text { Succinate- } \\
\text { glutamine }\end{array}$ & Glutamine \\
\hline 1021 (wild-type) & $3 \cdot 1$ & $3 \cdot 7$ & $4 \cdot 8$ \\
GSII $^{-}$ & $3 \cdot 2$ & $4 \cdot 1$ & $4 \cdot 9$ \\
GSI $^{-}$GSII $^{-}$ & $8 \cdot 1$ & $4 \cdot 5$ & $6 \cdot 9$ \\
GSI $^{-}$GSII $^{-}(+0.5 \mathrm{mM} \mathrm{MS})$ & $12 \cdot 6$ & $4 \cdot 6$ & $7 \cdot 0$ \\
\hline
\end{tabular}

Table 4. Labelling and accumulation of organic acids in S. meliloti 1021 and GS- mutant strains grown in succinateglutamine MM

S. meliloti strains were grown in succinate-glutamine $\left(10 \mathrm{mM}\right.$ each) MM. After 5 h growth, $0 \cdot 2 \mu \mathrm{Ci} \mathrm{m} l^{-1}\left(7 \cdot 4 \mathrm{kBq} \mathrm{m}^{-1}\right)$ each of $[1,4-$ $\left.{ }^{14} \mathrm{C}\right]$ succinate and $\left[2,3-{ }^{14} \mathrm{C}\right]$ succinate were added and 30 min later the concentration [nmol (mg protein) $\left.{ }^{-1}\right]$ of all organic acids (except $\beta$-OHB, as $\mathrm{PHB}$ ) and the radioactivity (c.p.m. nmol ${ }^{-1}$ ) were measured. For $\beta$-OHB (as PHB) measurement, $\beta$-OHB present in PHB was labelled with $\mathrm{L}_{-}\left[{ }^{14} \mathrm{C}\right]$ glutamine as described in Methods.

\begin{tabular}{|c|c|c|c|c|c|c|c|c|c|c|}
\hline \multirow[t]{2}{*}{ Organic acid } & \multicolumn{2}{|c|}{1021} & \multicolumn{2}{|c|}{$\mathrm{GSI}^{-}$} & \multicolumn{2}{|c|}{ GSII $^{-}$} & \multicolumn{2}{|c|}{$\mathrm{GSI}^{-} \mathrm{GSII}^{-}$} & \multicolumn{2}{|c|}{$\mathrm{GSI}^{-} \mathrm{GSII}^{-}(+1 \mathrm{mM} \mathrm{MS})$} \\
\hline & $\begin{array}{l}\text { Radio- } \\
\text { activity }\end{array}$ & Concn & $\begin{array}{l}\text { Radio- } \\
\text { activity }\end{array}$ & Concn & $\begin{array}{l}\text { Radio- } \\
\text { activity }\end{array}$ & Concn & $\begin{array}{l}\text { Radio- } \\
\text { activity }\end{array}$ & Concn & $\begin{array}{l}\text { Radio- } \\
\text { activity }\end{array}$ & Concn \\
\hline 2-Oxoglutaric acid & 4.05 & $9 \cdot 64$ & $4 \cdot 00$ & $12 \cdot 78$ & ND & ND & $0 \cdot 12$ & $4 \cdot 26$ & 0.06 & $28 \cdot 0$ \\
\hline Succinic acid & $50 \cdot 00$ & $193 \cdot 00$ & $38 \cdot 70$ & $120 \cdot 00$ & $43 \cdot 20$ & $120 \cdot 00$ & $22 \cdot 20$ & $498 \cdot 00$ & $17 \cdot 30$ & $82 \cdot 0$ \\
\hline$\gamma-\mathrm{OHB}$ & $4 \cdot 36$ & $10 \cdot 00$ & $3 \cdot 42$ & $5 \cdot 41$ & 2.99 & $11 \cdot 70$ & 0.44 & $17 \cdot 00$ & $0 \cdot 32$ & $20 \cdot 0$ \\
\hline$\beta$-OHB & $2 \cdot 98$ & $7 \cdot 80$ & $1 \cdot 10$ & $11 \cdot 60$ & $0 \cdot 67$ & $14 \cdot 80$ & $0 \cdot 19$ & $24 \cdot 70$ & 0.06 & $32 \cdot 5$ \\
\hline$\beta$-OHB (as PHB) & 0.04 & $7 \cdot 00$ & $0 \cdot 11$ & $10 \cdot 20$ & $0 \cdot 35$ & $13 \cdot 70$ & 1.76 & $25 \cdot 70$ & $2 \cdot 48$ & $35 \cdot 6$ \\
\hline
\end{tabular}

$R$. etli and S. meliloti lack functional NADPH-dependent GDH and ammonium is assimilated in these organisms by the GS-GOGAT pathway.

\section{Glutamine biosynthesis and incorporation of succinate- and glutamine-carbon into organic acids}

As reported elsewhere (Encarnación et al., 1995), S. meliloti 1021, as well as other species of rhizobia, accumulate PHB when grown in the presence of succinate with either ammonium or glutamine as the nitrogen source (Table 4). More PHB is accumulated by the $\mathrm{GSI}^{-} \mathrm{GSII}^{-}$doble mutant than by the wild-type strain, and accumulation is further increased when the GSIII inhibitor MS is present (Table 4). Thus, impairment of glutamine synthesis promotes the conversion of this amino acid to $\beta$-hydroxybutyric acid $(\beta$ $\mathrm{OHB}$ ) and $\gamma$-OHB, both of which are precursors of PHB (Hardman \& Stadtman, 1963). $\gamma$-OHB is derived from glutamine through the consecutive conversion of glutamate to $\gamma$-aminobutyric acid, succinic acid semialdehyde and finally to $\gamma$-OHB. $\gamma$-Hydroxybutyryl-CoA can be converted to $\beta$-hydroxybutyryl-CoA, which is hydrolysed to $\beta$-OHB (Hardman \& Stadtman, 1963).
The incorporation of label derived from succinate into 2-oxoglutarate, $\gamma$-OHB and $\beta$-OHB was determined after $5 \mathrm{~h}$ growth (Table 4$)$. The $\beta$-OHB measured in these experiments was that present in the polymeric form (PHB) and the following discussion of $\beta$-OHB pertains to the polymeric form. Labelling of $\beta$-OHB in the wild-type strain 1021 was much greater with $[1,4-$ $\left.{ }^{14} \mathrm{C}\right]$ succinate than with $\mathrm{L}-\left[\mathrm{U}-{ }^{14} \mathrm{C}\right]$ glutamine (Table 4). This finding is in accordance with that observed previously for Alcaligenes eutrophus. In this organism, conversion of succinate to acetyl-CoA and hence to $\beta$ $\mathrm{OHB}$ is known to be facile (Steinbüchel \& Schlegel, 1991). Label transfer from $\left[{ }^{14} \mathrm{C}\right]$ succinate to $\beta$-OHB in the $\mathrm{GSI}^{-} \mathrm{GSII}^{-}$double mutant was 16 -fold lower than that in the wild-type strain. In the presence of MS, the label in $\beta$-OHB in the double mutant was further decreased to $2 \%$ of the value obtained in the wild-type strain (Table 4). The opposite occurred with the label derived from $\mathrm{L}-\left[\mathrm{U}-{ }^{14} \mathrm{C}\right]$ glutamine. In this case, label in $\beta$ $\mathrm{OHB}$ was 44-fold greater in the absence of MS and 62 fold greater in the presence of MS, relative to the label incorporated into $\beta-\mathrm{OHB}$ in the wild-type strain. Label derived from $\mathrm{L}-\left[\mathrm{U}-{ }^{14} \mathrm{C}\right]$ glutamine in $\beta$-OHB in the three untreated $\mathrm{GS}^{-}$mutant strains was intermediate between 
Table 5. Excretion of organic acids from S. meliloti 1021 and GS- mutant strains grown in succinate-glutamine MM

Strains were grown in succinate-glutamine (10 $\mathrm{mM}$ each) $\mathrm{MM}$ as described in Methods. ND, Not detected.

\begin{tabular}{|c|c|c|c|c|c|}
\hline \multirow[t]{2}{*}{ Organic acid } & \multicolumn{5}{|c|}{$\begin{array}{l}\text { Concentration of extracellular organic acid } \\
{\left[\mu \mathrm{mol}(\mathrm{mg} \text { protein })^{-1}\right] \text { in strain: }}\end{array}$} \\
\hline & 1021 & $\mathrm{GSI}^{-}$ & $\mathrm{GSII}^{-}$ & GSI $^{-}$GSII $^{-}$ & $\begin{array}{c}\text { GSI GSII }^{-} \\
(+1 \mathrm{mM} \mathrm{MS})\end{array}$ \\
\hline 2-Oxoglutaric acid & $2 \cdot 05$ & $1 \cdot 35$ & $1 \cdot 17$ & $8 \cdot 94$ & $12 \cdot 10$ \\
\hline Malic acid & $1 \cdot 15$ & $0 \cdot 81$ & 0.95 & $1 \cdot 59$ & $2 \cdot 03$ \\
\hline$\gamma-\mathrm{OHB}$ & ND & $0 \cdot 39$ & $0 \cdot 25$ & $0 \cdot 96$ & $3 \cdot 23$ \\
\hline
\end{tabular}

that of the wild-type and that of the double mutant treated with MS (Table 4).

The smaller quantity of label incorporated from ${ }^{14} \mathrm{C}$ labelled succinate into 2-oxoglutarate, $\gamma$-OHB and $\beta$ $\mathrm{OHB}$ in the $\mathrm{GSI}^{-} \mathrm{GSII}^{-}$double mutant (with or without added MS) growing on succinate-glutamine MM, compared to the label incorporated into these organic acids in the wild-type strain, can only be partially explained by the increased concentration of these acids arising from a higher rate of glutamine catabolism in the double mutant (compare Tables 4 and 5). Table 5 shows that the $\mathrm{GSI}^{-} \mathrm{GSII}^{-}$double mutant grown in succinateglutamine $\mathrm{MM}$ (in the absence or presence of MS) excreted 4- to 6-fold greater amounts of 2-oxoglutarate than did the wild-type strain and 7-to 10 -fold greater amounts than did the single mutant (Table 5). Moreover, the $\mathrm{GSI}^{-} \mathrm{GSII}^{-}$strain in the presence of $\mathrm{MS}$ excreted almost twice as much malic acid as did the wild-type strain (Table 5). In addition, the $\mathrm{GSI}^{-} \mathrm{GSII}^{-}$double mutant excreted more $\gamma$-OHB than did the single mutant $\mathrm{GSI}^{-}$strain; this effect was greater in the double mutant treated with MS. The amount of $\gamma$-OHB excreted by the double mutant was $2 \cdot 5$ - and 8 -fold greater in the absence and in the presence of MS, respectively, than that excreted by the $\mathrm{GSI}^{-}$strain (Table 5).

In the presence of $\left[{ }^{14} \mathrm{C}\right]$ succinate-glutamine $\mathrm{MM}$, the specific radioactivities of intracellular 2-oxoglutarate and $\beta$-OHB in the double mutant (plus MS) compared to those in the 1021 wild-type strain were 68 -and 50 -fold lower, respectively (Table 4). However, the intracellular concentrations of these two organic acids in the double mutant (plus MS) were three- and fourfold greater, respectively, than those in the wild-type strain. Similarly, the specific activity of intracellular $\gamma$-OHB was 14 -fold lower, but its concentration was twofold greater, in the double mutant (plus MS) than in the wild-type strain (Table 4). In contrast, the specific activity of succinic acid was threefold lower in the double mutant (plus MS) than in the wild-type strain, but its concentration was not appreciably different in the two strains.

The data presented here indicate that in succinateglutamine MM, rhizobia transform glutamine-carbon into several organic acids, and that impairment of glutamine synthesis increases the rate of degradation of this amino acid. Indeed, under conditions of impaired glutamine synthesis, the carbon necessary for the synthesis of 2-oxoglutarate, $\gamma-\mathrm{OHB}$ and $\beta$-OHB acids is derived more readily from glutamine than from succinate. The proposition that glutamine is a more direct precursor of these organic acids than is succinate is supported by the finding that in the $\mathrm{GSI}^{-} \mathrm{GSII}^{-}$strain, incorporation of label derived from $\left[{ }^{14} \mathrm{C}\right]$ succinate into intracellular $\gamma-\mathrm{OHB}$ and $\beta-\mathrm{OHB}$ (in the presence of glutamine) is lower than that in the wild-type strain. The increase in labelling of $\beta-\mathrm{OHB}$ in the presence of succinate plus $\left[{ }^{14} \mathrm{C}\right]$ glutamine in the double mutant, relative to that in the wild-type strain, is also in accord with the greater utilization of glutamine in the double mutant versus the wild-type strain.

One explanation for the finding that glutamine oxidation to $\mathrm{CO}_{2}$ is lower than that of succinate in the CE3 wild-type strain of $R$. etli is that glutamine can be converted to glutamate and then decarboxylated to $\gamma$ aminobutyric acid, which in turn is converted to succinic acid semialdehyde, $\gamma$-OHB, $\beta$-OHB-CoA and $\mathrm{PHB}$ (Metzer \& Halpern, 1990; Miller et al., 1991). Thus, the 2-oxoglutaric acid derived from glutamine is a precursor of succinate in Rhizobium. When cells are grown in the presence of succinate and $\left[{ }^{14} \mathrm{C}\right]$ glutamine, succinate is labelled in $S$. meliloti (data not shown), and in glutamine-only medium this dicarboxylic acid is excreted in large amounts after $10 \mathrm{~h}$ incubation (data not shown).

\section{Role of GSI and GSII in the utilization of glutamine as a nitrogen and/or carbon source}

Glutamine synthesis occurs even when glutamine is the nitrogen source in succinate-containing medium. $S$. meliloti 1021 grows in succinate-glutamine MM with 3.7 $\mathrm{h}$ DT (Table 3 ). Under this condition, GSII is induced during the first $8 \mathrm{~h}$ of growth and GSI activity is decreased. At later incubation times, when GSII activity is diminished, GSI activity is induced (Fig. 3a). Similar changes in GS activity occur with $R$. etli CE3 (Fig. 3a) except that the specific activities of GSI and GSII are 


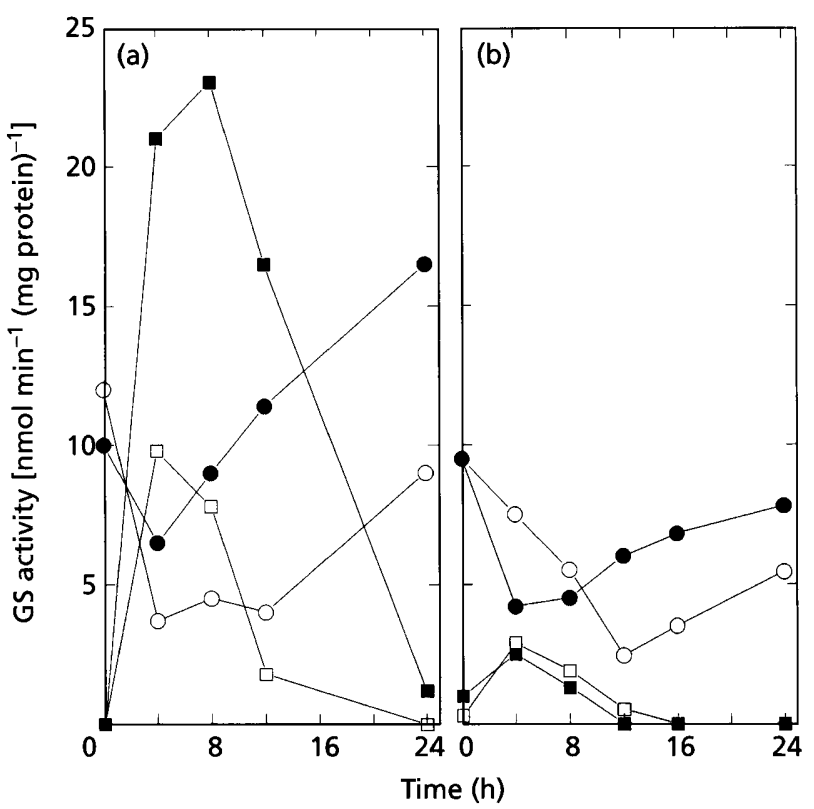

Fig. 3. GS specific activities during growth of $R$. meliloti 1021 and $R$. et $/ i$ CE3 under different conditions. Specific activities of GSI $(O, 0)$ and $G S I I(\square, \square)$ measured by their synthetase activity during growth of $R$. meliloti $1021(O, \square)$ and $R$. etli CE3 $(0$, ). (a) Growth on succinate-glutamine $(10 \mathrm{mM}$ each). MM (b) growth on $\mathrm{MM}$ with glutamine $(10 \mathrm{mM})$ as the sole nitrogen and carbon source.

higher. Evidently, GSII is induced when glutamine, in addition to succinate, is present (see Discussion). The addition of ammonium reduces the GSII activity to a level similar to that observed in succinate-ammonium MM (data not shown). However, when S. meliloti and $R$. etli wild-type strains are cultured in the presence of glutamine as the sole carbon and nitrogen source, growth is slower $(4 \cdot 8 \mathrm{~h} \mathrm{DT}$, Table 3$)$, almost no induction of GSII occurs, and GSI activity decreases during the first $12 \mathrm{~h}$ and increases slightly thereafter (Fig. 3b). Under these conditions of growth in glutamineonly medium, and in contrast to the case in which succinate and glutamine are present, ammonium is excreted into the medium (Table 2) (see also Durán \& Calderón, 1995). In addition, more ammonium and 2oxoglutarate are excreted when S. meliloti $\mathrm{GSI}^{-} \mathrm{GSII}^{-}$is grown in the presence of glutamine-only medium than when it is grown in the presence of glutamine-succinate MM (data not shown).

\section{DISCUSSION}

The relation between carbon utilization/oxidation and nitrogen assimilation was investigated in S. meliloti and $R$. etli. It was found that coordination exists between these metabolic processes. In contrast to other microorganisms, $S$. meliloti and $R$. etli utilize succinate as a carbon source more efficiently than they utilize glucose (see Results). Glutamine is a good nitrogen source in these species; however, succinate is a better carbon source than glutamine (see Results). Moreover, the ability to utilize glutamine-carbon in place of succinate is limited. In $S$. meliloti growing in succinate-glutamine $\mathrm{MM}$, the incorporation of succinate-carbon into amino acids and proteins, and oxidation of succinate are both decreased when glutamine synthesis is limited (as occurs, for example, in mutants lacking GSI, II and III) (Fig. $2 \mathrm{a}, \mathrm{c})$. Compared to the wild-type strain, the S. meliloti strains lacking GSI, II and III catabolize and oxidize more glutamine (Fig. 2b). However, growth of the mutant strains is limited, indicating that the oxidation of glutamine does not substitute effectively for the oxidation of succinate (see Results and Table 3). Although glutamine consumption is increased twofold, succinate utilization is reduced by more than $80 \%$ in the double mutant (see Results). Therefore, the reduced incorporation of label derived from $\left[{ }^{14} \mathrm{C}\right]$ succinate into amino acids and proteins, and the decreased oxidation to ${ }^{14} \mathrm{CO}_{2}$, cannot be explained by dilution of label resulting from glutamine metabolism. Moreover, in the GS mutants exposed to labelled succinate, the lower specific radioactivity of amino acids relative to those in the wild-type is the result of an absolute diminution in incorporated counts, and not to an increase in the amino acid concentrations (data not shown). Furthermore, for some amino acids, including glutamate and glutamine, a decrease in pool size is observed with the GS mutants (data not shown).

The labelling of $\gamma$-OHB in the wild-type strains (Tables 4, 5 and data not shown), indicates that glutamine after conversion to glutamate (Durán \& Calderón, 1995) is decarboxylated and that the $\gamma$-aminobutyric acid so formed is the source of this hydroxy acid (Hardman \& Stadtman, 1963; Miller et al., 1991). Accumulation of PHB in succinate-glutamine MM (Table 4) may be due to the conversion of $\gamma$-OHB to $\beta$-OHB (Hardman $\&$ Stadtman, 1963).

The extent of incorporation of labelled $\beta$-OHB (derived from $\left[{ }^{14} \mathrm{C}\right]$ succinate) into $\mathrm{PHB}$ in $S$. meliloti varies dramatically between wild-type and mutant strains (Table 4). When glutamine synthesis is limited, label in PHB is decreased. The extent of labelling relative to that in the wild-type is decreased several-fold in the GSI, GSII and double mutants. The relative decrease is 50 -fold in the double mutant treated with MS compared to the wild-type (Table 4). The dilution of label is presumably due to enhanced glutamine utilization and catabolism, and to a lower utilization of succinate (see Results). The reverse pattern, however, is observed when $\left[{ }^{14} \mathrm{C}\right]$ glutamine is the precursor of labelled $\beta$-OHB. In this case, labelling of $\beta$-OHB is low in the wild-type $S$. meliloti, several-fold higher in the GSI, GSII and double mutants, and 62-fold higher in the double mutant treated with MS (Table 4). In all cases of GS inhibition, PHB content only rises maximally fivefold. It is not clear whether the accumulation of PHB is a result of increased synthesis, decreased breakdown or both. Nevertheless, whatever the mechanisms of increase in PHB levels (Encarnación et al., 1995) in the presence of decreased glutamine synthesis, it is clear that the carbon for $\beta$-OHB synthesis is switched from succinate to glutamine. 
We believe that our present results are best explained by assuming that utilization and oxidation of succinate (or glucose) are driven by the cycling of ammoniumnitrogen and of glutamine-carbon through the GSGOGAT pathway and the degradation of glutamine (Durán et al., 1995; Table 1). The expenditure of $\mathrm{NADH}, \mathrm{ATP}$ and 2-oxoglutarate in this process (Helling, 1994) would drive the utilization/oxidation of succinate and glucose-carbon. It has been shown that optimization of energy flow requires the functioning of energy-dissipating reactions such as the cycling of glutamine (Stucki, 1980; Tempest, 1978; Mora, 1990; Fig. 1). Recently, it has been reported that a rise in ATP concentration inhibits glycolysis (Larsson et al., 1997). We propose that when glutamine cycling is interrupted by inhibiting glutamine synthesis, this leads to a large reduction in succinate utilization/oxidation. The cycle is so tightly coupled that loss of oxidation of succinatecarbon can only be offset to a very limited extent by increased glutamine oxidation. Interestingly, GSII is present in Rhizobium only during growth in succinate (Fig. 3a) or glucose (data not shown). This finding suggests a specific role for GSII in the GS-GOGAT cycle. In this regard, it is also interesting to note that a mutant of $R$. etli that is deficient in the transport of succinate accumulates a small amount of this compound, grows at a slow rate and does not express GSII (data not shown).

S. meliloti and $R$. etli growing in succinate-glutamine MM express GSII activity at a higher level than they do in succinate-glutamine-ammonium MM (Fig. 3a and data not shown). In the presence of ammonium, nitrogen is in excess and glutamine cycling can still operate efficiently with a low GSII, which results in an optimal oxidation of succinate. However, in succinate-glutamine MM these rhizobia grow at a slower rate than in succinate-ammonium $M M$, very possibly as result of carbon and nitrogen limitation (Table 3 and data not shown). In succinate-glutamine MM, nitrogen cycling involving glutamine may sequester some of the ammonia produced, allowing for the utilization/oxidation of some succinate and glutamine (see Results), and a nonoptimal growth response (Table 3). A different metabolic operation occurs when glutamine is the sole carbon and nitrogen source. In this case, GSI and GSII activities are the lowest detected (Fig. 3b). The growth rate is lower than when succinate is also present (Table 3), but since there is a very limited synthesis of glutamine, ammonia is abundantly excreted into the medium (Table 2), sparing the carbon of this amino acid for oxidation as also occurs in N. crassa (Calderón \& Mora, 1989; Table 2). However, it is possible that under these conditions the residual synthesis of glutamine still drives some oxidation of the succinate derived from glutamine. This would not be the case for the GS- mutant strain, which is the one that has the highest DT (Table 3).

The diminution in the rate of growth of the $\mathrm{GSI}^{-} \mathrm{GSII}^{-}$ double mutant grown in succinate-glutamine MM $(4 \cdot 5 \mathrm{~h}$ DT; Table 3) can be rationalized if it is assumed that this strain cannot synthesize glutamine, which in turn reduces succinate utilization and/or may be the result of a limitation in the succinate derived from glutamine (Table 4). In this regard, it is relevant that in comparison with the wild-type strain, in the $\mathrm{GS}^{-}$mutant plus MS, succinate dilution in $\beta$-OHB by glutamine is 50 -fold, in contrast with a threefold dilution of succinate labelling by glutamine (Table 4).

\section{ACKNOWLEDGEMENTS}

This work was supported by DGAPA grant IN213095 from the Universidad Nacional Autónoma de México, CONACyT grant 3309PB from Consejo Nacional de Ciencia y Tecnología, México.

We thank Georgina Hernández, Michael F. Dunn and Yolanda Mora for critically reviewing the manuscript, and Sandra Contreras and Luz Ma. Martínez for technical assistance in the determination of organic acids and amino acids. We also wish to thank Dr. Ronald Finn for providing the ${ }^{13} \mathrm{~N}$ isotope and the Cyclotron Facility of the Memorial Sloan Kettering Cancer Center, New York. We are also indebted to the unknown referees who took so much of their time with their deep and constructive criticism of this paper.

\section{REFERENCES}

Bender, R. A., Janssen, K. A., Resnick, A. D., Blumenberg, M., Foor, F. \& Magasanik, B. (1977). Biochemical parameters of glutamine synthetase from Klebsiella aerogenes. J Bacteriol 129, 1001-1009.

Bravo, A. \& Mora, J. (1988). Ammonium assimilation in Rhizobium phaseoli by the glutamine synthetase-glutamate synthase pathway. J Bacteriol 170, 980-984.

Bravo, A., Becerril, B. \& Mora, J. (1988). Introduction of the Escherichia coli gdhA gene into Rhizobium phaseoli: effect on nitrogen fixation. J Bacteriol 170, 985-988.

de Bruijn, F. J., Rossbach, S., Schneider, M., Ratet, P., Messmer, S., Szeto, W. W., Ausubel, F. M. \& Schell, J. (1989). R hizobium meliloti 1021 has three differentially regulated loci involved in glutamine biosynthesis, none of which is essential for symbiotic nitrogen fixation. J Bacteriol 171, 1673-1682.

Calderón, J. \& Mora, J. (1985). Glutamine cycling in Neurospora crassa. J Gen Microbiol 131, 3237-3242.

Calderón, J. \& Mora, J. (1989). Glutamine assimilation pathways in Neurospora crassa growing on glutamine as sole nitrogen and carbon source. J Gen Microbiol 135, 2699-2707.

Calderón, J., Morett, E. \& Mora, J. (1985). $\omega$-Amidase pathway in the degradation of glutamine in Neurospora crassa. J Bacteriol 161, 807-809.

Calderón, J., Cooper, A. J. L., Gelbard, A. S. \& Mora, J. (1989). ${ }^{13} \mathrm{~N}$ isotope studies of glutamine assimilation pathways in Neurospora crassa. J Bacteriol 171, 1772-1774.

Carlson, T. A., Martin, G. B. \& Chelm, B. K. (1987). Differential transcription of the two glutamine synthetase genes of Bradyrhizobium japonicum. J Bacteriol 169, 5861-5866.

Chiurazzi, M., Meza, R., Lara, M., Lahm, A., Defez, R., laccarino, M. \& Espín, G. (1992). The Rhizobium leguminosarum biovar phaseoli $\ln T$ gene, encoding glutamine synthetase III. Gene 119, 1-8.

Darrow, R. A. \& Knotts, R. R. (1977). Two forms of glutamine synthetase in free-living root-nodule bacteria. Biochem Biophys Res Commun 78, 554-559. 
Durán, S. \& Calderón, J. (1995). Role of the glutamine transaminase $\omega$-amidase pathway and glutaminase in glutamine degradation in Rhizobium etli. Microbiology 141, 589-595.

Durán, S., Du Pont, G., Huerta-Zepeda, A. \& Calderón, J. (1995). The role of glutaminase in Rbizobium etli: studies with a new mutant. Microbiology 141, 2883-2889.

Durán, S., Sánchez-Linares, L., Huerta-Saquero, A., Du Pont, G., Huerta-Zepeda, A. \& Calderón, J. (1996). Identification of two glutaminases in Rhizobium etli. Biochem Genet 34, 453-465.

Encarnación, S., Dunn, M., Willms, K. \& Mora, J. (1995). Fermentative and aerobic metabolism in Rbizobium etli. J Bacteriol 177, 3058-3066.

Espín, G., Palacios, R. \& Mora, J. (1979). Glutamine metabolism in nitrogen-starved conidia of Neurospora crassa. J Gen Microbiol 115, 59-68.

Espín, G., Moreno, S., Wild, M., Meza, R. \& laccarino, M. (1990). A previously unrecognized glutamine synthetase expressed in Klebsiella pneumoniae from the $g \ln \mathrm{T}$ locus of Rhizobium leguminosarum. Mol Gen Genet 223, 513-516.

Hardman, J. K. \& Stadtman, T. C. (1963). Metabolism of $\omega$-amino acids. IV. $\gamma$-Aminobutyrate fermentation by cell-free extracts of Clostridium aminobutyricum. J Biol Chem 238, 2088-2093.

Helling, R. B. (1994). Why does Escherichia coli have two primary pathways for synthesis of glutamate? J Bacteriol 176, 4664-4668.

Hernández, G. \& Mora, J. (1986). Glutamine synthesis regulates sucrose catabolism in Neurospora crassa. J Gen Microbiol 132, 3315-3323.

Hernández, G., Mora, Y. \& Mora, J. (1986). Regulation of glutamine synthesis by glycine and serine in Neurospora crassa. $J$ Bacteriol 165, 133-138.

Larsson, Ch., Nilsson, A., Blomberg, A. \& Gustafsson, L. (1997). Glycolytic flux is conditionally correlated with ATP concentration in Saccharomyces cerevisiae: a chemostat study under carbon- or nitrogen-limiting conditions. J Bacteriol 179, 72437250 .
Law, J. H. \& Slepecky, R. A. (1961). Assay of poly- $\beta$-hydroxybutyric acid. J Bacteriol 82, 33-36.

Lomnitz, A., Calderón, J. \& Mora, J. (1987). Functional analysis of ammonium assimilation enzymes in Neurospora crassa. J Gen Microbiol 133, 2333-2340.

Metzer, E. \& Halpern, Y. S. (1990). In vivo cloning and characterization of the gabCTDP gene cluster of Escherichia coli K-12. $J$ Bacteriol 172, 3250-3256.

Miller, R. W., McRae, D. G. \& Joy, K. (1991). Glutamate and $\gamma$ aminobutyrate metabolism in isolated Rhizobium meliloti bacteroids. Mol Plant-Microbe Interact 4, 37-45.

Mora, J. (1990). Glutamine metabolism and cycling in Neurospora crassa. Microbiol Rev 54, 293-304.

Mora, J., Salceda, R. \& Sánchez, S. (1972). Regulation of arginase activity by intermediates of the arginine biosynthetic pathway in Neurospora crassa. J Bacteriol 110, 870-877.

Osburne, M. S. \& Signer, E. R. (1980). Ammonium assimilation in Rhizobium meliloti. J Bacteriol 143, 1234-1240.

Ronzio, R. A. \& Meister, A. (1968). Phosphorylation of methionine sulfoximine by glutamine synthetase. Proc Natl Acad Sci USA 59, 164-170.

Shatters, R. G., Liu, Y. \& Kahn, M. L. (1993). Isolation and characterization of a novel glutamine synthetase from Rhizobium meliloti. J Bacteriol 268, 469-475.

Steinbüchel, A. \& Schlegel, H. G. (1991). Physiology and molecular genetics of poly ( $\beta$-hydroxy-alkanoic acid) synthesis in Alcaligenes eutrophus. Mol Microbiol 5, 535-542.

Stucki, J. W. (1980). The optimal efficiency and the economic degrees of coupling of oxidative phosphorylation. Eur J Biochem 109, 269-283.

Tempest, D. W. (1978). The biochemical significance of microbial growth yields : a reassessment. Trends Biochem Sci 3, 180-184.

Received 3 March 1998; revised 21 May 1998; accepted 1 June 1998. 